\title{
Mathematical model for predicting stress-strain behavior of low calcium fly-ash based geopolymer concrete
}

\author{
Nutakki Sai Ketana ${ }^{1 *}$, Srinivasa Reddy $\mathrm{V}^{2}, M V$ Seshagiri $\mathrm{Rao}^{3}$, and $S$ Shrihari ${ }^{4}$ \\ ${ }^{1} \mathrm{M}$. Tech (Structural Engineering), Department of Civil Engineering, GRIET, Hyderabad, India. \\ ${ }^{2}$ Professor of Civil Engineering, GRIET, Hyderabad, India. \\ ${ }^{3}$ Professor of Civil Engineering, CVR College of Engineering, Hyderabad, Telangana. \\ ${ }^{4}$ Professor of Civil Engineering, VJIT, Hyderabad, India.
}

\begin{abstract}
The focus of the study was to identify the stress strain behavior of geo polymer concrete and salient parameters that influence the mixture proportions and the properties of low calcium fly ash- based geo polymers concrete. To develop geopolymer concrete the chemical proportions are alkaline liquid solution/fly-ash ratio $=0.5$, Sodium silicate/sodium hydroxide ratio $=2.5,16 \mathrm{M} \mathrm{NaOH}$ and $\mathrm{SiO}_{2} / \mathrm{Na}_{2} \mathrm{O}$ ratio $=2.0$. The geopolymer concrete mixes have shown improved stress values for the same strain levels compared to that of controlled concrete mix. Normalized stress strain curves are used to compare the behaviours of geopolymer concrete. It can be observed that geopolymer concrete has improved strains for the same stress when compared to conventional concrete. Geopolymer concrete mixes have shown improved stress values for the same strain levels compared to that of controlled concrete mixes.
\end{abstract}

\section{Introduction}

Early investigations on alkali activated binder (AAB) date back to the beginning of the 20th century thanks to pioneering work by Kühl in Germany which was on vitreous slags activated with alkali materials [1]. However, it was only in the last decade that they gained international attention as alternative to Portland cement (PC) based binders, mainly due to the potential reduction of associated $\mathrm{CO}_{2}$ emissions and for their inherent properties such as high strength, good resistance to chemical degradation, thermal stability and fire resistance, among others [2]. Factors such as dosage of alkali solutions, water content, elevated curing temperatures $\left(60\right.$ to $\left.100{ }^{\circ} \mathrm{C}\right)$ and curing time are considered to be the important factors influencing the properties of geopolymer or alkali activated concretes (AAC). The parameters considered in the design procedure for obtaining required compressive strength and workability were water to geopolymer solid ratio, alkali solution/fly ash and alkali solution/water ratios. The focus of the study was to identify the stress strain behavior of geo polymer concrete and salient parameters that influence the mixture proportions and the properties of low calcium fly ash- based geo polymers concrete.

\section{Preparation Of Geopolymer Concrete}

The Basic Materials required for Geopolymer Concrete are Fine Aggregate, Coarse Aggregate, Fly ash, Sodium Silicate $\left(\mathrm{Na}_{2} \mathrm{SiO}_{3}\right)$, Sodium Hydroxide $(\mathrm{NaOH})$, Ground Granulate Blast Slag (GGBS). Sodium Hydroxide is in the form of Pallets and Sodium Silicate is in Liquid Form. Sodium Hydroxide pellets are taken and dissolved in water. It is strongly advised that the sodium hydroxide solution be made 24 hours ahead of time, since it will solidify into a semi-solid liquid condition if left unattended for more than 36 hours. As a result, the ready-to-use solution must be utilised within this time frame. To create a solution with the appropriate concentration, the solids must be dissolved in water. The molar concentration of sodium hydroxide solution might differ. The mass of $\mathrm{NaOH}$ solids in a solution changes with the solution's concentration. The focus of the study was to identify the stress strain behaviour of geo polymer concrete. The Basic Materials required for Geopolymer Concrete are Fine Aggregate, Coarse Aggregate, fly ash, Sodium Silicate $\left(\mathrm{Na}_{2} \mathrm{SiO}_{3}\right)$, Sodium Hydroxide $(\mathrm{NaOH})$, Ground Granulate Blast

${ }^{1}$ Corresponding author: ketananutakki@gmail.com 
Slag (GGBS). Sodium Hydroxide is in the form of flakes and Sodium Silicate is in Liquid Form.

\section{Sodium Hydroxide Solution}

Pellets of sodium hydroxide are ingested and dissolved in water. It is strongly advised that the sodium hydroxide solution be made 24 hours ahead of time, since it will solidify into a semi-solid liquid condition if left unattended for more than 36 hours. As a result, the ready-to-use solution must be utilised within this time frame. To create a solution with the appropriate concentration, the solids must be dissolved in water. The molar concentration of sodium hydroxide solution might differ. The mass of $\mathrm{NaOH}$ solids in a solution changes with the solution's concentration.

\section{Mix Proportions}

For each $1 \mathrm{~m}^{3}$ of concrete,

- Weight of fly-ash $=400 \mathrm{~kg}$

- Alkaline liquid solution/fly-ash ratio $=0.5$ (adopted from past literature)

- Weight of AAS $=400 * 0.5=200 \mathrm{~kg}$

- $\quad$ Sodium silicate/sodium hydroxide ratio=2.5 (adopted from past literature)

- $\quad 16 \mathrm{M} \mathrm{NaOH}$ (adopted from past literature)

- $\mathrm{SiO}_{2} / \mathrm{Na}_{2} \mathrm{O}$ ratio=2.0 (adopted from past literature)

- $\quad$ Mass of $\mathrm{NaOH}=200 /(1+2.5)=57.14 \mathrm{~kg}$

- Mass of $\mathrm{Na}_{2} \mathrm{SiO}_{3}=200-57.14=142.86 \mathrm{~kg}$

- $\quad$ Mass of aggregate $=2400-400-200=1800 \mathrm{~kg}$
- Ratio of fine aggregate: coarse aggregate $(20 \mathrm{~mm})=0.4: 0.6$

- $\quad$ Mass of sand $=0.4 * 1800=720 \mathrm{~kg}$

- Mass of coarse aggregate $=1080 \mathrm{~kg}$

- $\mathrm{Na}_{2} \mathrm{SiO}_{3}$ : $\mathrm{NaOH}$ : fly ash: sand: coarse aggregate $(20 \mathrm{~mm})=0.358: 0.142: 1: 1.8: 2.7$

The above GPC mix ingredients are considered based on various trial mixes and strength achieved is equivalent to that of M20 grade normal concrete.

\section{Stress Strain Behaviour}

The aim of this study is to determine the stress-strain behaviour of Geo polymer concrete experimentally. Cylinders of standard size $150 \times 300 \mathrm{~mm}$ are cast, cured for 28 days and tested in uni-axial compression under strain control as per IS: 516-1999 to understand the stress-strain behaviour of Geopolymer concrete considered. The test setup for stress-strain measurements is shown in Fig.1

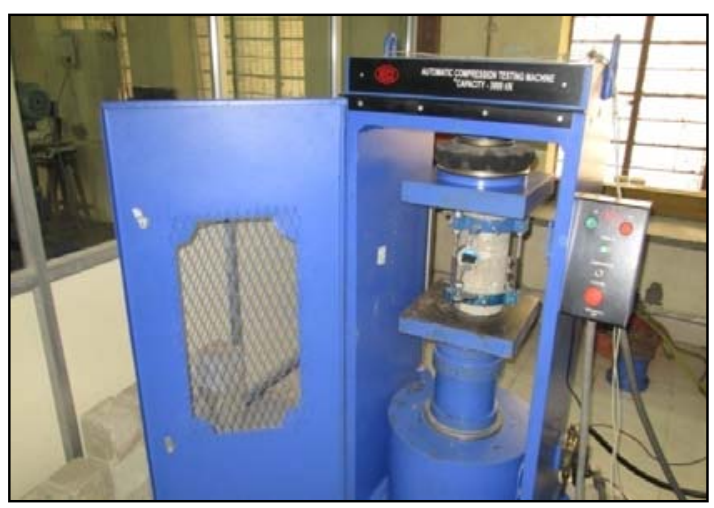

Fig.1.: Test setup for stress-strain measurements

Table 1. Experimental stress strain values of Conventional Concrete

\begin{tabular}{|c|c|c|c|}
\hline Strain & Stress N/mm ${ }^{2}$ & Normalized stress & Normalized strain \\
\hline 0 & 0 & 0 & 0 \\
\hline 0.00008 & 2.26 & 0.079 & 0.018 \\
\hline 0.00022 & 4.43 & 0.155 & 0.050 \\
\hline 0.00044 & 6.58 & 0.230 & 0.101 \\
\hline 0.00079 & 8.45 & 0.295 & 0.181 \\
\hline 0.00129 & 11.82 & 0.413 & 0.295 \\
\hline 0.00153 & 13.79 & 0.481 & 0.350 \\
\hline 0.00178 & 15.83 & 0.553 & 0.407 \\
\hline 0.00202 & 17.09 & 0.597 & 0.462 \\
\hline 0.00228 & 19.23 & 0.671 & 0.522 \\
\hline 0.00263 & 21.62 & 0.755 & 0.602 \\
\hline 0.00324 & 24.36 & 0.851 & 0.741 \\
\hline 0.00358 & 25.42 & 0.888 & 0.819 \\
\hline 0.00402 & 27.68 & 0.966 & 0.920 \\
\hline 0.00437 & 28.64 & 1.000 & 1.000 \\
\hline 0.00482 & 28.41 & 0.992 & 1.103 \\
\hline
\end{tabular}




\begin{tabular}{|l|l|l|l|}
\hline 0.00508 & 27.67 & 0.966 & 1.162 \\
\hline 0.00518 & 23.54 & 0.822 & 1.185 \\
\hline
\end{tabular}

Table 2. Experimental stress strain values of Geopolymer Concrete

\begin{tabular}{|c|c|c|c|}
\hline Strain & Stress N/mm² & Normalized stress & Normalized strain \\
\hline 0.0000 & 0 & 0 & 0 \\
\hline 0.0001 & 2.26 & 0.074 & 0.018 \\
\hline 0.0002 & 4.43 & 0.145 & 0.061 \\
\hline 0.0004 & 6.58 & 0.216 & 0.104 \\
\hline 0.0008 & 8.05 & 0.264 & 0.151 \\
\hline 0.0013 & 11.82 & 0.387 & 0.247 \\
\hline 0.0015 & 13.79 & 0.452 & 0.283 \\
\hline 0.0018 & 15.83 & 0.519 & 0.337 \\
\hline 0.0020 & 17.09 & 0.560 & 0.380 \\
\hline 0.0023 & 19.23 & 0.630 & 0.419 \\
\hline 0.0026 & 21.62 & 0.708 & 0.493 \\
\hline 0.0032 & 23.85 & 0.781 & 0.566 \\
\hline 0.0036 & 25.25 & 0.827 & 0.622 \\
\hline 0.0040 & 28.88 & 0.946 & 0.785 \\
\hline 0.0044 & 29.79 & 0.976 & 0.885 \\
\hline 0.0048 & 30.34 & 0.994 & 0.935 \\
\hline 0.0051 & 30.52 & 1.000 & 1.000 \\
\hline 0.0052 & 29.02 & 0.951 & 1.029 \\
\hline 0.0000 & 26.62 & 0.872 & 1.056 \\
\hline 0.0001 & 24.89 & 0.816 & 1.066 \\
\hline
\end{tabular}

\section{Stress - Strain Curves for} Conventional and Geopolymer concretes

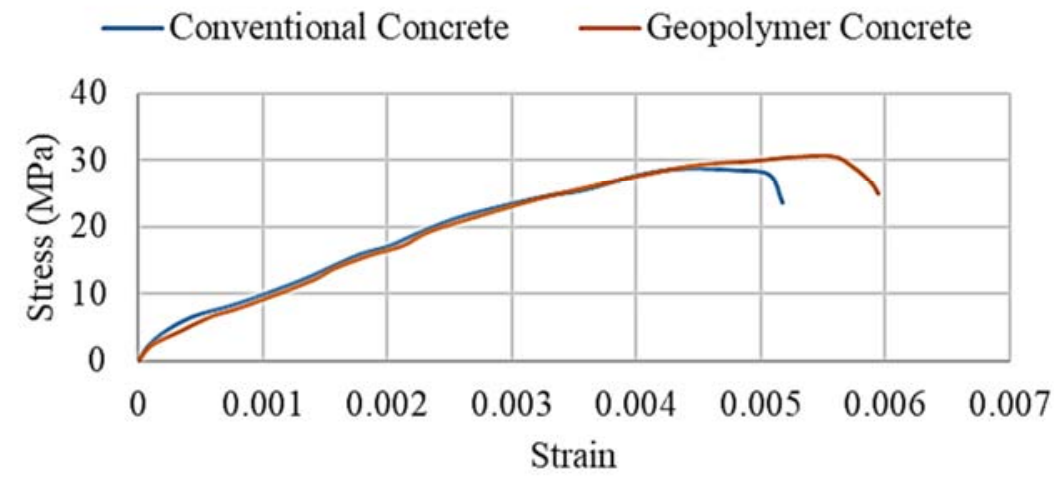

Fig. 1. Experimental stress strain values of Conventional and Geopolymer Concrete 


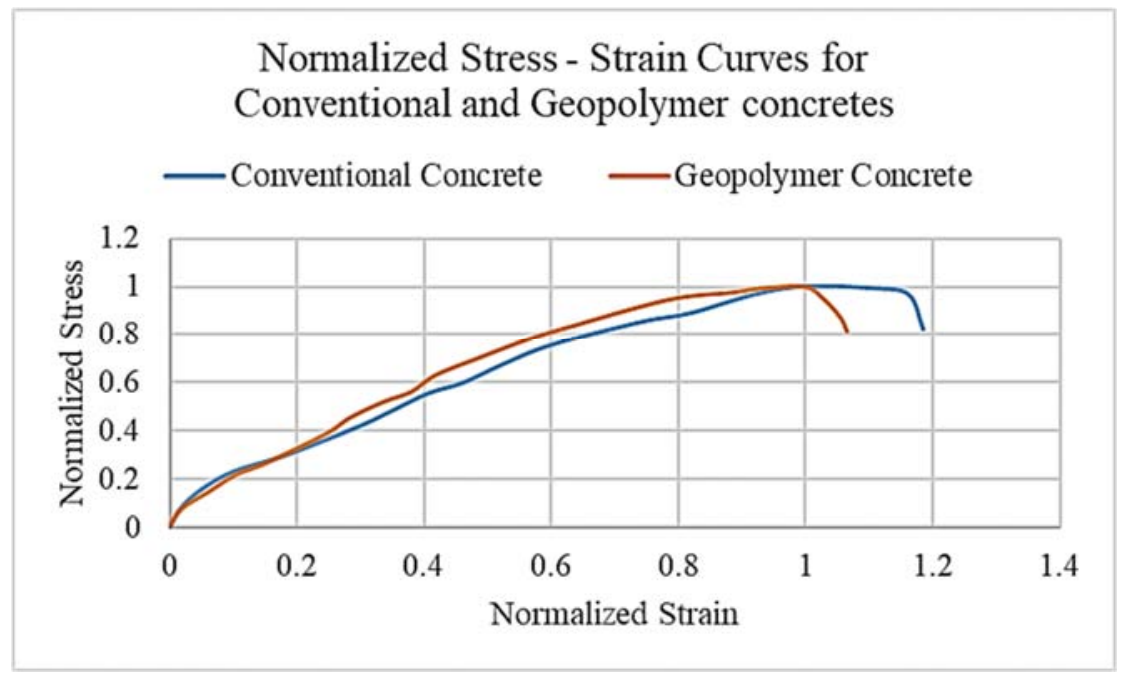

Fig. 2. Experimental normalized stress strain values of Geopolymer Concrete

Table 3. Peak stress values and their corresponding strains

\begin{tabular}{|c|c|c|c|}
\hline \multicolumn{2}{|c|}{ Conventional Concrete } & \multicolumn{2}{c|}{ Geopolymer concrete } \\
\hline $\begin{array}{c}\text { Peak Stress } \\
\mathrm{f}_{\mathrm{o}}\end{array}$ & $\begin{array}{c}\text { Corresponding strain at } \\
\text { peak stress } \\
\in_{\mathrm{o}}\end{array}$ & $\begin{array}{c}\text { Peak Stress } \\
\mathrm{f}_{\mathrm{o}}\end{array}$ & $\begin{array}{c}\text { Corresponding strain at } \\
\text { peak stress } \\
\in_{\mathrm{o}}\end{array}$ \\
\hline 28.64 & 0.00437 & 30.52 & 0.00558 \\
\hline
\end{tabular}

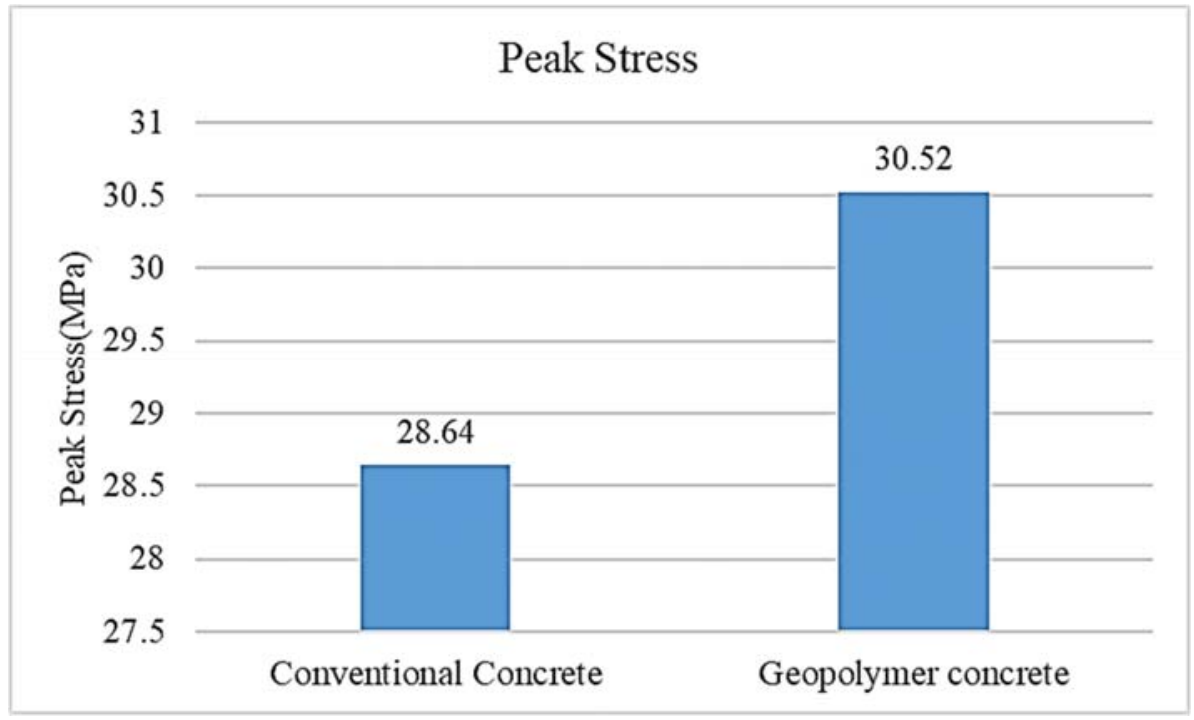

Fig 3. Peak stress values for Conventional and Geopolymer Concrete 


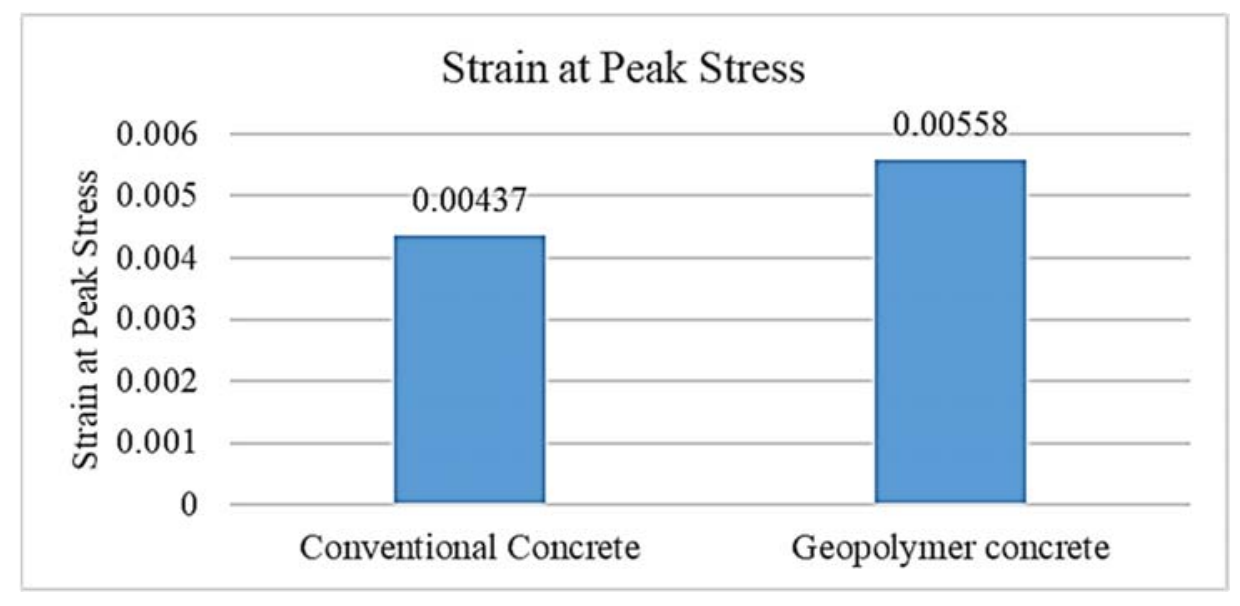

Fig 4. Peak stress values for Conventional and Geopolymer Concrete

The stress-strain curve for mix is drawn using the values of stresses and strains, using the average values of the three cylinders' findings. The related normalised stress-strain values are derived by dividing each stress value by the peak stress and dividing each strain value by strain at peak strain from the stress-strain values of controlled and geo polymer concrete mixes. The average normalised stress-strain curves for controlled and geo polymer concrete are displayed using the normalised stress-strain values of the two concrete mixes. From the observations made from stress-strain curves of all the controlled and geopolymer concrete mixes, the stress-strain behavior is observed to be almost similar. The only difference is that geo polymer concrete mixes have shown improved stress values for the same strain levels compared to that of controlled concrete mixes. It can be observed from stress strain curves that for geopolymer and conventional concrete, the shape of the ascending part of the stress-strain curve is more linear and steeper. The strain at peak stress is slightly higher, and the slope of the descending part is steeper in geopolymer concrete as compared to normal strength concrete. That was due to the decrease in the extent of internal micro cracking in geopolymer concrete. Strains attained are more in geopolymer concrete indicating its ductile nature of its microstructure.

\section{Conclusions}

The following conclusions may be derived from the experimental data gathered during the course of this study:

1. When compared to a controlled concrete mix, the geo polymer concrete mixes showed better stress values at the same strain levels.

2. The average strain at peak stress for controlled and geo polymer concrete is extremely near to the strain at peak stress for controlled concrete in axial compression, which is 0.002 according to IS 456-2000.
3. The stress-strain curves for controlled and geo polymer concrete obtained in the experiment show a similar pattern. When compared to controlled concrete mixes, geopolymer concrete mixes showed improved stress values for the same strain levels. The form of the ascending section of the stress-strain curve for typical concrete is more linear and steeper, as can be seen from stress-strain curves.

4. Normalized stress strain curves are used to compare the behaviours of geopolymer concrete. It can be observed that geopolymer concrete has improved strains for the same stress when compared to conventional concrete.

\section{References}

1. Srinivas. T, Abhignya. G and Ramana Rao. N.V, A Review on Geopolymer RCC Beams made with Recycled Coarse Aggregate, E3S Web of Conferences, ICMED, 10-12 July 2020, India (2020).

2. T. Srinivas, S. V. Srinidhi and N.V. Ramana Rao, A Review on Flexural Behavior of RCC Beams Made with Geopolymer Concrete, E3S Web of Conferences, ICMED, 10-12 July 2020, India (2020).

3. T. Srinivas, P. Bhavana, and N. V. Ramana Rao, Effect of Manufactured Sand on Flexural Behavior of Geopolymer RCC Beams: A review, E3S Web of Conferences, ICMED, 1012 July 2020, India (2020).

4. T. Srinivas and N.V.Ramana Rao, IJCIET, Volume 10, 510 (2019).

5. K. Sai Gopi, Dr. T. Srinivas and S. P. Raju V, E3S Web of Conferences ICMED 184, 01084GRIET, 28-29 February, https://doi.org/10.1051/e3sconf/202018401108 4(2020)

6. Kavitha, Merugu; Prasad, Dinkar; Bobba, Phaneendra Babu: IET Electric Power 
Applications, 2019, 13, (8), p. 1184-1192

7. Jagannadha Kumar, M.V., Jagannadha Rao, K., Dean Kumar, B., Srinivasa Reddy, V., Int. J. of Civil Eng. and Tech., 9(7), pp. 1133-1141 (2018)

8. Ganta, J.K., Seshagiri Rao, M.V., Mousavi, S.S., Srinivasa Reddy, V., Bhojaraju, C., Structures 28, pp. 956-972 (2020)

9. Naidu, K.S.S.T., Rao, M.V.S., Reddy, V.S., Int. J. of Innov. Tech. and Explor. Eng.g (IJITEE), 8(9 Special Issue 2), pp. 641-642 (2019)

10. Chandana Priya, C., Seshagiri Rao, M.V., Srinivasa Reddy, V., Int. J. of Civil Eng. and Tech., 9(11), pp. 2218-2225 (2018)

11. M. Kavitha, P. B. Bobba and D. Prasad, 2016 IEEE 6th International Conference on Power Systems (ICPS), 2016, pp. 1-6

12. Satya Sai Trimurty Naidu, K., Seshagiri Rao, M.V., Srinivasa Reddy, V., Int. J. of Civil Eng. and Tech., 9(11), pp. 2383-2393 (2018)

13. Supriya, Y., Srinivasa Reddy, V., Seshagiri Rao, M.V., Shrihari, S., Int. J. of Rec. Tech. and Engi., 8(3), pp. 5381-5385 (2019)

14. Kotkunde, N., Krishna, G., Shenoy, S.K., Gupta, A.K., Singh, S.K. International Journal of Material Forming, 10 (2), pp. 255-266 (2017)

15. Govardhan, D., Kumar, A.C.S., Murti, K.G.K., Madhusudhan Reddy, G. Materials and Design, 36, pp. 206-214. (2012)

16. A.U. Haq, A. K. Kavit, T. Rao, T. Buddi, D. Baloji, K. Satyanarayana, S. K. Singh, Materials Today: Proceedings, 18, 4589 (2019)

17. Kumar, P., Singhal, A., Mehta, S., Mittal, A. Journal of Real-Time Image Processing, 11 (1), pp. 93-109. (2016)

18. Srinivas Rao J, S K Tummala, Kuthuri N R, Indonesia Journal of Electrical Engg. \& Computer Science, 21 (723), 2020

19. Raghunadha Reddy, T., Vishnu Vardhan, B., Vijayapal Reddy, P. International Journal of Applied Engineering Research, 11 (5), pp. 30923102 (2016)

20. Hussaini, S.M., Krishna, G., Gupta, A.K., Singh, S.K. Journal of Manufacturing Processes, 18, pp. 151-158 (2015) 